\title{
Do urban African dwellers pay a premium for food quality and, if so, how much? An investigation of the Malian fonio grain market
}

\author{
Sandrine DURY*, Véronique MEURIOT** \\ * Cirad, UMR Moisa, F-34000 Montpellier, France \\ e-mail: sandrine.dury@cirad.fr \\ ** Cirad, Arena, F-34000 Montpellier, France
}

Summary - Very little data is available concerning the valuation of quality on existing food markets in SubSabaran Africa. Using data collected from a survey of fonio (a cereal) retail markets conducted in Bamako, Mali, Africa and a bedonic price Partial Least Square regression method, this study shows that most quality attributes declared as important by consumers have a specific hedonic price that is different from zero. This is interpreted as a result of the efficient performance of so-called traditional informal markets. Among the valued attributes, some are physical (colour, degree of milling) and thus relatively easy to assess, while the assessment of others (category or country of origin) are more complicated for both parties to the transaction. These attributes, however, also bave specific hedonic prices. Informal norms and a certain amount of trust are thus present in these markets and should not be underestimated. The inclusion of buyer characteristics in the model is justified by the differences in bargaining power, which are essentially linked with different levels of experience buying or using the product. We showed that women were getting better prices for the same product quality. The premiums paid for quality varied from 1 to $14 \%$ of the price. These estimates bave confirmed the other few estimates done in African food markets.

Keywords: fonio, cereal, quality, bedonic prices, PLS method, empirical investigation

Les urbains africains paient-ils une prime pour la qualité des aliments et si oui, combien? Une enquête sur le marché du grain de fonio au Mali

Résumé - Il existe très peu d'études concernant la valorisation de la qualité sur les marchés alimentaires en Afrique Sub-saharienne. La présente contribution montre, à partir de données sur le marché de détail du fonio (une céréale) à Bamako au Mali, et à partir d'une estimation des prix hédoniques par la méthode des moindres carrés partiels (PLS) que la plupart des attributs de qualité importants pour les consommateurs ont un prix hédonique différent de zéro. Ce résultat signifie que ce marché informel fonctionne suffisamment bien pour permettre une segmentation des produits selon différents niveaux de qualité. Parmi les attributs valorisés, certains sont physiques (couleur, niveau de décorticage) et relativement faciles à évaluer, tandis que d'autres sont plus difficiles à évaluer par les différents acheteurs et vendeurs (catégorie ou type de fonio, pays d'origine). Pourtant ces derniers attributs ont également un prix hédonique spécifique. Un certain niveau de confiance et des normes informelles sont ainsi nécessairement présents et ne doivent pas être sous-estimés. On a par ailleurs inclus dans le modèle certaines caractéristiques des acheteurs reflétant leur pouvoir de négociation, lié en partie à leur expérience. Cela a montré que les femmes obtiennent de meilleurs prix que les hommes pour la même qualité de produit. Les primes payées pour la qualité varient de 1 à $14 \%$ et ces estimations confirment les autres rares estimations réalisées sur les marchés alimentaires africains.

Mots-clés : fonio, céréale, qualité, prix hédoniques, méthode PLS, recherche empirique

JEL descriptors: $\mathrm{C} 13, \mathrm{C} 25, \mathrm{C} 51, \mathrm{D} 12, \mathrm{O} 55$ 


\section{Acknowledgements:}

This work was financed through the European Inco project FONIO "Upgrading quality and competitiveness of fonio for improved livelihoods in West Africa". Sandy BLANCHER ${ }^{1}$, JeanFrançois CRUZ2, Fanta BORE GUINDO ${ }^{3}$, Djibril DRAME ${ }^{3}$, Nicolas BRICAS', Lamissa DIAKITE $^{3}$, Geneviève FLIEDEL, Franck GALTIER ${ }^{1}$ and Michel SIMIONI ${ }^{4}$ are warmly thanked for their contributions in terms of survey design, data collection, understanding of the cereal processing, and comments on an earlier version of this paper. 1. CIRAD, UMR MOISA, Montpellier, France. 2. CIRAD, UMR QUALISUD, Montpellier, France. 3. IER, Institut d'Economie Rurale, Bamako, Mali. 4. INRA, UMR GREMAQ, Toulouse, France. The authors also thank warmly the two referees of the review for their accurate advices.

\section{Introduction}

The quality of staple food in very poor countries - especially those in West Africa is seldom questioned by agricultural and food economists. This is because it is overshadowed by other important questions such as availability (quantity available for consumption) or affordability (people's ability to access food), two pillars of the food security concept. However, questions concerning quality, quantity, and price are interrelated at all levels of the food production-trade-processing-consumption chains (Egg et al., 2006). It is indeed quite straightforward to assume that markets expand more easily (in this case, farmers farm more cereals for sale, traders trade more, and consumers buy more) if trading rules (the majority of which are not written in West Africa) exist and are respected. Among these rules, the common definitions of produce and their characteristics, the clear and shared knowledge/information about produce, as well as the stability of these definitions are keystones.

In spite of very little available empirical material, it is commonly said that "low quality food" prevails in Africa (Vanderplas, 2009) and that formal certification schemes should be promoted (Masters and Sanogo, 2002).

This study is an empirical contribution that seeks to answer the following: do urban African consumers pay for quality attributes of produce? For which attributes and for how much? The question is not: how much are they ready to pay? But rather, how much are they actually paying? We are not concerned with consumers' willingness or intent, but really the current paid premium on existing urban markets. This not only captures the ability of consumers to pay for different quality attributes and to express their preferences, but also that of the different market stakeholders, which results in differentiated quality attributes for the same product.

There are actually very few published studies and accurate data related to this question. Langyinto et al., 2003, and 2004, published a vast study concerning the premium paid for different characteristics of cowpea (Vigna unguiculata (L.) Walp) in West and Central Africa. Based on real prices paid in 16 markets in Ghana, Cameroon, Nigeria, and Senegal, the authors estimated different premiums ranging from $0.67 \%$ to $18 \%$ of the average retail price paid for various quality attributes such as the grain size, the "eye" or grain colour, etc. Their study "indicates that quality characteristics are very important in West African food markets" and that "even low income consumers are willing to pay a premium for products that match their preferences, and they are vigilant in identifying products that do not meet their standards". 
Basing their assertions on rice consumption surveys conducted in Ivory Coast and Nigeria in 2000, Lançon et al. (2004) insisted upon the fact that quality attributes - such as cleanliness, standardization, and ability to swell (the result of which one gets a higher cooked volume for the same dry weight) - are key factors in the consumers' preference for imported rice over local rice. In other words, they showed that urban consumers paid a premium for cleanliness and standardization. Using their data from Bouake, Ivory Coast (op. cit., p. 112), we estimated that imported rice represented $68 \%$ of total consumption whereas local rice was only $32 \%$. The prices weighed by quantity were respectively $279 \mathrm{FCFA} / \mathrm{kg}$ and $252 \mathrm{FCFA} / \mathrm{kg}$. This means that more than twothirds of the population paid a premium of about $10 \%$ to satisfy their preferences regarding the quality of rice. The other third, according to the authors, were either very poor ( $20 \%$ of the total sample) or came from a specific region and were used to eating a specific category of rice $(10 \%)$.

Vandeplas et al. (2009) showed that the premium paid by consumers for better quality rice was higher in India (up to $45 \%$ ) than in Madagascar (10\% maximum), which is a poorer country. Similarly, they argued that tomatoes of "good quality" (not rotten) were relatively more expensive in India compared to Madagascar.

\subsection{Fonio as a case study}

Our study concerned fonio (Digitaria exilis) - a cereal grown in West Africa. This cereal is a "minor" product in terms of production (in Mali, for instance, it represents less than $1 \%$ of all cereals consumed, and total production in Africa was about 365,000 metric tons in 2005, Cruz, 2009 quoting FAO), yet it is well known and appreciated by most consumers (Konkobo-Yameogo et al., 2004) and the market is expanding both in West African and European cities (Cruz, 2009). The miniscule size of this market acts as an advantage since it is easier to observe and analyse it in comparison to larger grain markets, such as millet (Pennisetum glaucum, (L.) R. Br) or sorghum (Sorghum bicolor (L.) Moench). There is no evidence that consumers behave differently nor similarly when buying fonio compared to millet or sorghum, which are the real staple foods of the inhabitants of the Sahelian region in West Africa. Despite this lack of "real" proof, one could arguably liken fonio to these cereals on the basis that it too is a cereal that is grown in the same regions and sold by the same type of sellers within the same kind of city markets to the final consumers (Bessler and Kergna, 2003, our observations). We hypothesise that the behaviours addressed in this study can at the very least be extrapolated for the study of other cereals. More generally, and according to several previous empirical studies (Dury et al., 2002; Cheyns, 1998 and 2006; Bricas and Cheyns, 2003; Lançon et al., 2004; Alpha et al., 2009; Langyintuo et al., 2003-2004), we suppose that this example illustrates at least one part of the West African urban consumers' attitudes toward food quality: i.e. most people, even the very poor, have strong quality requirements. They may not be able to afford to fulfil all of them, but they deal with them on a daily basis and use different means to "optimize" a complex system of preferences during the purchase, home processing, or cooking of food. 


\section{Methodology}

Our methodology was based on the classical (1966) perspective of Lancaster's quality of produce, which is considered as a sum of quality attributes or characteristics, and on Rosen's (1974) hedonic estimation method, which provided a theoretical background to empirical estimations of the implicit or hedonic price of each of these characteristics. We collected the data directly through the observation of specific retail transactions in different markets of the city. After analysing the data using descriptive statistics (tables 1,2) and a Partial Least Square (PLS) regression (table 3), we then ran different simulations (table 4).

\subsection{Data collection}

Our fieldwork was organized into two main activities. Using several open-ended individual interviews and 6 focus groups, the first aimed to determine the various attributes according to several different consumers. This also gave us most of the interpretation cues regarding what matters and why for fonio buyers and consumers. The second part aimed to collect market data on real fonio purchases using structured closed questionnaires. Five different marketplaces in Bamako were selected for their representativeness of fonio and, more generally, of grain markets (Bessler and Kergna, 2003). Although some of these markets have both wholesale and retail activities, we limited our scope to the retail purchases, as it was important for our research to track the variation of prices and quality at the very end of the food marketing chain.

The collection of data was implemented during September and October 2006. All 174 purchases of traditional products were surveyed in five traditional open markets. The data collected concerned the price actually paid and the characteristics of (i) the supplier (market type), (ii) the product attributes (type, size, colour, etc.), (iii) the buyer (age, education level, sex, etc.).

Most characteristics were declared by the buyer and were not assessed by an external expert or system of measure. While perhaps dissatisfying for those who prefer to objectivise the aspects of quality, this method does provide valuable information. For instance (table 2), $28 \%$ of the buyers declared that they did not know the origin nor the size of the grain, and $44 \%$ of them stated that they had no idea about the hardness of the grain. This can be interpreted into two ways: (i) these buyers did not really care about these aspects or (ii) they were not able to distinguish between the different modalities because they lacked information (problem of signal). The regression results gave more insight. In any case, it is clear that "white" is a perception declared by a specific person - the buyer - and has not been measured.

Bargaining is omnipresent in African food markets, and prices, even if not always discussed, are always up for negotiation. For most staple foods, including cereal and fonio, the produce is sold in bulk, and there are neither price tags nor any other tags or written labels. Hence the buyer is not helped by any formal institutions to determine what kind of product he/she is looking at. Instead the buyer relies on his/her personal abilities to assess the quality of the produce (using his/her knowledge) and very rarely relies an external formal institution. 
As we observed in many different food retail markets in Cameroon and Mali - and as reported by other authors like Clark, 1994, in Ghana or Chaléard, 1996, in Ivory Coast - it is often the case that the price itself is not discussed, but rather the quantity of product for a given amount of money. The client asks the seller for a "gift" (which is the addition of extra product), which is either accepted or not. In the end, it is the price per kilogram $(\mathrm{kg})$ that is decreasing, but not the "cost" itself. In our survey, we carefully reported all the details of the transaction concerning the amount of money paid, the purchased quantity, and the real paid price per $\mathrm{kg}$ (which is actually a calculated variable: amount of money paid divided by quantity in $\mathrm{kg}$ ).

\subsection{Addition of some seller characteristics to the standard hedonic model}

In addition to the intrinsic characteristics of the product (as proposed by Rosen, 1974), we supposed that observed price variations also depended on the partners of the transaction. Buyers have different bargaining powers (see for instance Harding et al., 2003) according to their individual characteristics.

As Harding et al. (2003) showed for homes in the United States, bargaining power depends on personal characteristics of the buyers or sellers, such as gender or the presence of school-age children in the family. Harding et al. (2003), Colwell and Munneke (2006), and Kumbhakar and Parmenter (2009) dealt with "big" durable goods, such as houses or offices, which were seldom ever bought in a lifetime. For those markets, considering both seller and buyer characteristics are necessary. In our case, we dealt with consumption goods, which are generally sold in very small quantities by a few sellers to many different buyers. Therefore, we made the assumption that sellers were more or less all the same in each marketplace and that most variations concerned the buyers.

As a consequence, the hedonic function was written as follows:

$$
Y=\alpha+\beta X+\varepsilon
$$

Where $\mathrm{Y}$ is the observed selling unit price of the good (in FCFA ${ }^{1} / \mathrm{kg}$ ), $\mathrm{X}$ is a vector of the characteristics of the good itself and the transaction - including technical characteristics, quantity sold, and place of the transaction, as well as characteristics of the buyer that were supposed to influence his/her bargaining power.

$\alpha$ is the constant term, $\beta$ the parameters related to the characteristic $X$, and $\varepsilon$ the error.

\subsection{Estimation of a Hedonic price model with the Partial Least Square Regression}

Since most exogenous variables were discrete (qualitative), this model was first estimated using the Analysis of Covariance (ANCOVA) procedure. Several different ANCOVA were tested, including those with no specification, stepwise, or best $\mathrm{R}^{2}$ procedures. The results were somehow difficult to analyse because they were quite

\footnotetext{
${ }^{1}$ Franc de la Communauté Financière Africaine. 656 FCFA = 1 euro (fixed parity).
} 
sensitive to the chosen procedure and reference. This was mainly due to the collinearity between variables. This is a general statement of the fact that the regression of a quantitative variable over a large number of qualitative variables generates collinearity problems related to two different main causes. First, qualitative variables are less discriminatory than continuous ones: there are a few different modalities of each variable. Second, exogenous variables were very closely collinear (for example, cleanliness with colour).

To deal with these collinearity problems, we used the Partial Least Square (PLS) method proposed by Wold et al. (1984). As Stoica and Söderström (1998) mentioned: "In ill-conditioned linear regression problems, in which regressors are nearly collinear, the use of Ordinary Least Squares (OLS) is generally to be avoided owning to its poor performance, such as large mean square errors (MSE). (...) Of the previously mentioned biased estimators, the PCA and PLS appear to be among the best." In a first stage, the method consists in computing an axis called "principal component", which is a linear combination of the exogenous variables, or more precisely, of the different modalities of the exogenous variables $\left(\mathrm{t}_{1}\right)$. This axis resumes the maximum variance of the model, as in a principal component analysis:

$$
\begin{aligned}
& t_{1}=w_{11} x_{1}+\ldots+w_{1 p^{x}} \\
& \text { where } w_{1 j}=\frac{\operatorname{cov}\left(x_{j}, y\right)}{\sqrt{\sum_{j=1}^{p} \operatorname{cov}^{2}\left(x_{j}, y\right)}}
\end{aligned}
$$

$\mathrm{x}_{1} \ldots \mathrm{x}_{\mathrm{p}}$ are all the modalities of all the characteristics $\mathrm{Xi}$.

In a second stage, we regressed the price (endogenous variable) over this axis $\left(\mathrm{t}_{1}\right)$ :

$$
\mathrm{Y}=\mathrm{y}_{1}+\mathrm{c}_{1} \mathrm{t}_{1}+\varepsilon^{\prime}
$$

Thus,

$$
\mathrm{Y}=\mathrm{y}_{1}+\mathrm{c}_{1} \mathrm{w}_{11} \mathrm{x}_{1}+\ldots \mathrm{c}_{1} \mathrm{w}_{1 \mathrm{p}} \mathrm{x}_{\mathrm{p}}+\varepsilon^{\prime}
$$

Where $\mathrm{y}_{1}$ is the constant term, $\mathrm{c}_{1}$ the parameters related to the modalities $\mathrm{x}_{\mathrm{i}}$, and $\varepsilon^{\prime}$ the error.

This method does not allow estimating t-Student coefficients to control the level of significance of the variables. Instead, the Variable Importance in the Projection (VIP) statistic was used as proposed by Tenenhaus (1998). As a rule of thumb, we chose the cut-off value at 0.8 , as many practitioners usually do.

\subsection{Estimation of the model and simulations}

Different sets of variables $\mathrm{X}_{\mathrm{i}}$ were tested (see justification below) and each corresponding PLS regression is referred to here as a "model". The results of three of them - "model 1" to "model 3" - are presented in table 3. Regressions were done using the XLSTAT software package. Once the "best" model had been chosen (model 2, table 3), 
we ran simulations. Using the estimated parameters of model 2, we calculated the prices given by the model for different fonio purchases (knowing the market, type, milling degree, colour, origin of the product, profession, age, and education of the buyer, the model gave us the expected price). We chose a reference and then changed one characteristic after another to assess its specific effect on the final price (see table 4).

The estimation's results could be used for a simulation (table 4). For example, a non-professional, uneducated aged woman would buy brown, badly "decorticated" fonio from Mali at the Medina market (market-1) at the price of $351 \mathrm{FCFA} / \mathrm{kg}$. We chose this specific transaction (a coupling of product and buyer characteristics) as a "reference" because: (i) it represents an average realistic combination of attributes that makes sense from an empirical point of view, and (ii) the estimate of the parameter is one of the estimate extremes. For example, the market-1 parameter equals -9.55 , while the other extreme is the parameter of market -5 , which equals +35.46 .

Each simulation ( $\operatorname{sim} 1$ to 9 , table 4 ) consists in calculating the expected price for a slightly different coupling (product/person): sim1, where the market is different; $\operatorname{sim} 2$, where the type of fonio is different; etc., until $\operatorname{sim} 9$, where the time spent in school is different. When the characteristic had more than two modalities, the simulation was done using the other extreme, for instance, market-5.

In a sense, the difference calculated in the two last lines of table 4 , in absolute and relative values, is an estimate of the maximum value of the hedonic price of each characteristic (market in sim1, type in $\operatorname{sim} 2$, etc.), while the value of parameters (in model 2, table 3) represents the hedonic price of each modality.

\section{Results and discussion}

\subsection{Results of the qualitative survey and description of chosen variables}

Table 1 gives the summary statistics of the two quantitative variables of the model. On average, the unit price was $410 \mathrm{FCFA} / \mathrm{kg}$, ranging from a minimum of 250 and a maximum of 650 with a coefficient of variation equal to 17.

The purchased amounts were quite small, as expected. They varied from 0.5 to $100 \mathrm{~kg}$ with a median of 2 and a mean of $5.5 \mathrm{~kg}$.

Table 1. Descriptive statistics of quantitative variables

\begin{tabular}{lcc}
\hline \multicolumn{1}{c}{ Variable name } & Price & Quantity \\
\hline \multicolumn{1}{c}{ Definition } & Unit price & Purchased amount \\
\hline Unit & FCFA $/ \mathrm{Kg}$ & $\mathrm{Kg}$ \\
Minimum & 174 & 174 \\
Maximum & 250 & 0.5 \\
Median & 650 & 100.0 \\
Mean & 400 & 2.0 \\
Standard deviation & 410 & 5.5 \\
Variation coefficient $(\%)$ & 69.7 & 14.3 \\
& 17 & 262 \\
\hline
\end{tabular}


Table 2 presents the list of the characteristics and their modalities used in the initial regression (model 1, table 3). During the focus groups, all the variables in table 2 were quoted several times as important at one stage or another of the purchase, the processing (including milling, cleaning, washing, and cooking), and the consumption of the cereal. As such, these variables potentially impacted the price of the product. This is the reason why we have kept all of them in a first stage of regression (model 1, table 3).

Among the different attributes, three concerned the quality of the transformation process (fonio "type", level of milling, and cleanliness), three concerned the physical aspect of the grain (size, hardness, and colour), and one its geographical origin (country of production).

During the course of our different interviews, it became clear that the country of origin - as avowed by the seller - was considered by many of the buyers as proxy of the fonio quality. Even if the exact definition of this quality varied from one person to another, there was a kind of consensus (with a few exceptions) that fonio from Guinea was of better quality than that from Mali, mainly because of its cleanliness and good degree of milling. It was difficult to say which was coming first at the interview level since most buyers - except for professionals who usually dealt with larger quantities displayed a certain amount of confusion about their ability to assess the "good quality" criteria.

The fonio types that appear here refer to how they were named by most stakeholders. It is related to the processed level. Grain in Bamako markets can be milled to various degrees: the operation of milling consists in removing the envelopes of the grain. A first type is the so-called "decorticated". It is a mixture of milled and non-milled grain. The second type is called "whitened" or "milled", during which the entire grain is dehusked. The third type is called "milled and washed": the pip, the bran, and all dust have been removed through a complex treatment with water. The definition of these categories and their boundaries were ambiguous at the end of the first phase of the survey, even if almost all consumers or other stakeholders were able to describe at least one category. This is why we finally included all of them in one single regression and did not split the model into different segments, as we had done in an earlier version (Dury et al., 2007).

Finally, these discussions underlined the differences between people. There was general consensus on some issues, such as the effect of gender: men, except cereal traders, were said to be very incompetent regarding the evaluation of cereal quality in the market, while women were obviously more competent than men. Direct observation as well as interviews told us that the level of competence was quite different according to experience. In the models, we used three variables to capture the experience effect: age, professionalism, and region of birth. A "professional" refers to an individual buying fonio for processing (often cooking) and selling. This activity was usually done on a regular basis, thus these professionals were logically seen as better equipped to assess the fonio quality and negotiate the prices.

Many disputes concerned the role of wealth on the ability to recognize the "good" fonio. Some said rich people just did not care and did not spend time assessing the quality of their fonio purchases because they had servants to clean and prepare it. Others 
Table 2. Descriptive statistics of the qualitative variables

\begin{tabular}{|c|c|c|c|c|c|c|c|}
\hline & $\begin{array}{l}\text { Variable } \\
\text { name }\end{array}$ & Modality & Definition & $\mathrm{n}$ & $\begin{array}{l}\text { Mean } \\
\text { price }\end{array}$ & $\begin{array}{l}\text { Sd of } \\
\text { price }\end{array}$ & $\begin{array}{l}\mathrm{CV} \text { of } \\
\text { price }\end{array}$ \\
\hline \multirow{5}{*}{$\begin{array}{l}\text { Characteristics } \\
\text { of the } \\
\text { transaction }\end{array}$} & Market & 1 & Medina market & 46 & 375 & 38 & 10 \\
\hline & & 2 & Korofina market & 44 & 394 & 16 & 4 \\
\hline & & 3 & Lafiabougou market & 19 & 382 & 25 & 6 \\
\hline & & 4 & Magnanbougou market & 44 & 400 & 56 & 14 \\
\hline & & 5 & Riverside market & 21 & 562 & 52 & 9 \\
\hline \multirow{23}{*}{$\begin{array}{l}\text { Characteristics } \\
\text { of the } \\
\text { product }\end{array}$} & Type & 1 & Decorticated & 57 & 360 & 30 & 8 \\
\hline & & 2 & Milled & 101 & 413 & 47 & 11 \\
\hline & & 3 & Milled and washed & 16 & 566 & 54 & 10 \\
\hline & Milling & 1 & Badly decorticated & 25 & 351 & 29 & 8 \\
\hline & & 2 & Well decorticated & 55 & 387 & 37 & 10 \\
\hline & & 3 & Very well decorticated & 94 & 438 & 78 & 18 \\
\hline & Clean & 1 & Very dirty & 16 & 369 & 27 & 7 \\
\hline & & 2 & Dirty & 58 & 416 & 79 & 19 \\
\hline & & 3 & Clean & 77 & 410 & 68 & 17 \\
\hline & & 4 & Very clean & 23 & 422 & 65 & 15 \\
\hline & Colour & 1 & White & 111 & 418 & 69 & 16 \\
\hline & & 2 & Cream-white & 14 & 475 & 66 & 14 \\
\hline & & 3 & Grey & 21 & 391 & 67 & 17 \\
\hline & & 4 & Red/brown & 28 & 357 & 32 & 9 \\
\hline & Origin & 1 & Guinea & 102 & 418 & 63 & 15 \\
\hline & & 2 & Mali & 23 & 353 & 33 & 9 \\
\hline & & 3 & Unknown & 49 & 426 & 84 & 20 \\
\hline & Size & 1 & Big & 44 & 429 & 83 & 19 \\
\hline & & 2 & Small & 82 & 406 & 71 & 18 \\
\hline & & 3 & Unknown & 48 & 398 & 49 & 12 \\
\hline & Hard & 1 & Hard & 88 & 412 & 79 & 19 \\
\hline & & 2 & Soft & 9 & 461 & 108 & 23 \\
\hline & & 3 & Unknown & 77 & 401 & 48 & 12 \\
\hline \multirow{13}{*}{$\begin{array}{l}\text { Characteristics } \\
\text { of the buyer }\end{array}$} & Prof & 0 & Non-professional & 127 & 424 & 75 & 18 \\
\hline & & 1 & Professional & 47 & 372 & 32 & 9 \\
\hline & Age & 1 & Age $\leq 20 y$ & 27 & 393 & 52 & 13 \\
\hline & & 2 & $20<$ age $\leq 50$ & 124 & 404 & 62 & 15 \\
\hline & & 3 & Age $>50$ & 23 & 461 & 105 & 23 \\
\hline & Sex & 1 & Man & 19 & 504 & 90 & 18 \\
\hline & & 2 & Woman & 155 & 398 & 58 & 15 \\
\hline & Region & 1 & With fonio & 96 & 403 & 57 & 14 \\
\hline & & 2 & No fonio & 78 & 419 & 83 & 20 \\
\hline & School & 1 & $\begin{array}{l}\text { No school or max primary } \\
\text { school }\end{array}$ & 128 & 398 & 57 & 14 \\
\hline & & 2 & Secondary or higher level & 46 & 444 & 90 & 20 \\
\hline & Hsize & 1 & $<5$ adults & 121 & 409 & 67 & 16 \\
\hline & & 2 & $\geq 5$ adults & 53 & 426 & 82 & 19 \\
\hline Total & & & & 174 & 410 & 70 & 17 \\
\hline
\end{tabular}

CV here stands for Coefficient of Variation, a normalized measure of dispersion. It is the ratio of the Standard deviation (Sd) to the mean. 
thought rich people were exactly like others: some care and some did not, some knew and some did not. It was difficult to capture a good proxy of the wealth of the interviewees during the survey; hence we used the "level of education" as an indication of the purchasing power of the interviewees. $74 \%$ of the sample either never went to school or attended only until the primary level. Only $25 \%$ exceeded primary level education.

\subsection{Results of the estimation of the hedonic model and simulations}

The presented regressions were done only on one axis since the information given by a second axis was very poor. Table 3 presents the Variable Importance in Projection (VIP) of each modality and the value of the estimated parameters for the three models. Several other models were run, but are not presented here since they gave quite similar results. The best model according to the $\mathrm{Q}^{2}$ criteria (model 2, table 3) is also the simplest.

The results of regression 1 (model 1) showed that both places of sale, product characteristics (type of fonio, level of milling, origin, and colour), and several buyer characteristics (sex, "professional", school level, and age) had a significant impact on the price. On the other hand, the quantity, cleanliness, size, and hardness of the grain, the birth region of the buyer, and the number of adults in the household had no specific effect on the price.

The most important modalities regarding the VIP indicators were by decreasing order: the Riverside market, the fonio types, the sex, and the level of milling.

The results were quite surprising concerning quantity and cleanliness. In terms of quantity, one would have expected a significant coefficient, but the VIP was less than 0.6 , which is a very low value; however, in comparison to the insignificant showings all other regressions, including those not presented here, this result seems robust.

Model 2 is the same as model 1 minus all the variables that did not have a single significant modality. It is interesting to note that estimated coefficients did not change tremendously here.

Model 3 (model 2 minus "cleanliness" and plus "type") was run because of the high-expected correlation between the type and the cleanliness of fonio. Coefficients did not change much here either and cleanliness did not become significant.

Altogether, model 2 was considered the most efficient and reliable model, thus was used for further simulations.

\section{Place of sale}

Two markets, Medina (1) and Riverside (5), have a significant influence on the retail price in the model. Medina is the largest central market and directly receives products from all production areas and Niarela, the wholesale market of Bamako for millet (Bessler and Kergna, 2003) and for fonio (coming from Guinea or different regions in Mali). Medina is also both a retail and wholesale market. Change from one to the other represents 45 FCFA (13\%) (sim1, table 4). The price paid in Riverside is much higher than that paid in Medina. This confirms empirical evidence and gives more precise figures. 
Table 3. Value of parameters and Variable Importance in the Projection (VIP)

\begin{tabular}{|c|c|c|c|c|c|c|c|c|}
\hline \multicolumn{3}{|c|}{ Model 1} & \multicolumn{3}{|c|}{ Model 2} & \multicolumn{3}{|c|}{ Model 3} \\
\hline Constant & 425.170 & VIP & Constant & 424.22 & VIP & Constant & 425.86 & VIP \\
\hline Qty_kg & 0.135 & 0.502 & & & & & & \\
\hline Market-1* & -9.021 & 1.033 & Market-1* & -9.55 & 0.86 & Market-1* & -11.39 & 0.99 \\
\hline Market-2 & -3.964 & 0.447 & Market-2 & -4.20 & 0.37 & Market-2 & -5.01 & 0.43 \\
\hline Market-3 & -6.092 & 0.493 & Market-3 & -6.45 & 0.41 & Market-3 & -7.69 & 0.47 \\
\hline Market-4 & -2.434 & 0.275 & Market-4 & -2.58 & 0.23 & Market-4 & -3.07 & 0.26 \\
\hline Market-5* & 33.507 & 2.833 & Market-5* & 35.46 & 2.35 & Market-5* & 42.31 & 2.71 \\
\hline Type-1* & -14.254 & 1.736 & Type-1* & -15.08 & 1.44 & & & \\
\hline Type-2 & 1.496 & 0.192 & Type-2 & 1.58 & 0.16 & & & \\
\hline Type-3* & 33.239 & 2.493 & Type-3* & 35.17 & 2.07 & & & \\
\hline Milling-1* & -13.156 & 1.198 & Milling-1* & -13.92 & 0.99 & Milling-1* & -16.61 & 1.15 \\
\hline Milling-2* & -6.453 & 0.779 & Milling-2* & -6.83 & 0.92 & Milling-2* & -8.15 & 0.75 \\
\hline Milling-3* & 12.133 & 1.569 & Milling- $3 *$ & 12.84 & 1.30 & Milling-3* & 15.32 & 1.50 \\
\hline Clean-1 & -8.710 & 0.653 & & & & Clean-1 & -11.00 & 0.63 \\
\hline Clean-2 & 1.760 & 0.215 & & & & Clean-2 & 2.22 & 0.21 \\
\hline Clean-3 & 0.107 & 0.014 & & & & Clean-3 & 0.14 & 0.01 \\
\hline Clean-4 & 2.701 & 0.237 & & & & Clean-4 & 3.41 & 0.23 \\
\hline Colour-1 & 4.532 & 0.565 & Colour-1 & 4.80 & 0.47 & Colour-1 & 5.72 & 0.54 \\
\hline Colour-2* & 13.755 & 0.971 & Colour-2* & 14.56 & 0.81 & Colour-2* & 17.37 & 0.93 \\
\hline Colour-3 & -4.057 & 0.343 & Colour-3 & -4.29 & 0.28 & Colour-3 & -5.12 & 0.33 \\
\hline Colour-4* & -12.102 & 1.154 & Colour-4* & -12.81 & 0.96 & Colour-4* & -15.28 & 1.11 \\
\hline Origin-1 & 2.375 & 0.304 & Origin-1 & 2.51 & 0.25 & Origin-1 & 3.00 & 0.54 \\
\hline Origin-2* & -12.567 & 1.105 & Origin-2* & -13.30 & 0.92 & Origin-2* & -15.87 & 1.06 \\
\hline Origin-3 & 4.278 & 0.499 & Origin-3 & 4.53 & 0.30 & Origin-3 & 5.40 & 0.48 \\
\hline Size-1 & 5.011 & 0.565 & & & & & & \\
\hline Size-2 & -1.291 & 0.167 & & & & & & \\
\hline Size-3 & -3.129 & 0.363 & & & & & & \\
\hline Hard-1 & 0.902 & 0.117 & & & & & & \\
\hline Hard-2 & 10.505 & 0.604 & & & & & & \\
\hline Hard-3 & -3.003 & 0.387 & & & & & & \\
\hline Prof-0* & 9.968 & 1.149 & Prof-0* & 10.55 & 0.95 & Prof-1* & 12.59 & 1.10 \\
\hline Prof-1* & -9.968 & 1.149 & Prof-1* & -10.55 & 0.95 & Prof-0* & -12.59 & 1.10 \\
\hline Age-1 & -3.901 & 0.367 & Age-1 & -4.13 & 0.30 & Age-1 & -4.93 & 0.35 \\
\hline Age-2 & -3.902 & 0.458 & Age-2 & -4.13 & 0.38 & Age-2 & -4.93 & 0.44 \\
\hline Age-3* & 11.425 & 1.004 & Age-3* & 12.09 & 0.83 & Age-3* & 14.43 & 0.96 \\
\hline Sex-1* & 20.486 & 1.658 & Sex-1* & 21.68 & 1.38 & Sex-1* & 25.87 & 1.59 \\
\hline Sex-2* & -20.486 & 1.658 & Sex $-2 *$ & -21.68 & 1.38 & Sex-2* & -25.87 & 1.59 \\
\hline Region-1 & -3.143 & 0.406 & & & & & & \\
\hline Region-2 & 3.143 & 0.406 & & & & & & \\
\hline School-1* & -8.989 & 1.029 & School-1* & -9.51 & 0.85 & School-1* & -11.35 & 0.99 \\
\hline School-2* & 8.989 & 1.029 & School-2* & 9.51 & 0.85 & School-2* & 11.35 & 0.99 \\
\hline Hsize-1 & -4.671 & 0.558 & & & & & & \\
\hline Hsize-2 & 4.671 & 0.558 & & & & & & \\
\hline Quality index $\left(Q^{2}\right)$ & 0.623 & & & 0.630 & & & 0.570 & \\
\hline
\end{tabular}

$*$ VIP $>0.8$. 
Table 4. Simulations

\begin{tabular}{|c|c|c|c|c|c|c|c|c|c|c|}
\hline & Reference & $\begin{array}{l}\text { Sim1 } \\
\text { Market }\end{array}$ & $\begin{array}{l}\text { Sim2 } \\
\text { Type }\end{array}$ & $\begin{array}{l}\text { Sim3 } \\
\text { Milling }\end{array}$ & $\begin{array}{c}\text { Sim4 } \\
\text { Colour }\end{array}$ & $\begin{array}{c}\text { Sim5 } \\
\text { Origin }\end{array}$ & $\begin{array}{l}\text { Sim6 } \\
\text { Prof }\end{array}$ & $\begin{array}{l}\text { Sim7 } \\
\text { Age }\end{array}$ & $\begin{array}{l}\text { Sim8 } \\
\text { Sex }\end{array}$ & $\begin{array}{l}\text { Sim9 } \\
\text { School }\end{array}$ \\
\hline Constant & 424.22 & 424.22 & 424.22 & 424.22 & 424.22 & 424.22 & 424.22 & 424.22 & 424.22 & 424.22 \\
\hline Market-1 & -9.55 & & -9.55 & -9.55 & -9.55 & -9.55 & -9.55 & -9.55 & -9.55 & -9.55 \\
\hline \multicolumn{11}{|l|}{ Market-2 } \\
\hline \multicolumn{11}{|l|}{ Market-3 } \\
\hline \multicolumn{11}{|l|}{ Market-4 } \\
\hline Market-5 & & 35.46 & & & & & & & & \\
\hline Type-1 & -15.08 & -15.08 & & -15.08 & -15.08 & -15.08 & -15.08 & -15.08 & -15.08 & -15.08 \\
\hline \multicolumn{11}{|l|}{ Type-2 } \\
\hline Type-3 & & & 35.17 & & & & & & & \\
\hline Milling-1 & -13.92 & -13.92 & -13.92 & & -13.92 & -13.92 & -13.92 & -13.92 & -13.92 & -13.92 \\
\hline \multicolumn{11}{|l|}{ Milling-2 } \\
\hline Milling-3 & & & & 12.84 & & & & & & \\
\hline \multicolumn{11}{|l|}{ Colour-1 } \\
\hline Colour-2 & & & & & 14.56 & & & & & \\
\hline \multicolumn{11}{|l|}{ Colour-3 } \\
\hline Colour-4 & -12.81 & -12.81 & -12.81 & -12.81 & & -12.81 & -12.81 & -12.81 & -12.81 & -12.81 \\
\hline \multicolumn{11}{|l|}{ Origin-1 } \\
\hline Origin-2 & -13.30 & -13.30 & -13.30 & -13.30 & -13.30 & 0.00 & -13.30 & -13.30 & -13.30 & -13.30 \\
\hline Origin-3 & & & & & & 4.53 & & & & \\
\hline Prof-0 & 10.55 & 10.55 & 10.55 & 10.55 & 10.55 & 10.55 & & 10.55 & 10.55 & 10.55 \\
\hline Prof-1 & & & & & & & -10.55 & & & \\
\hline Age-1 & & & & & & & & -4.13 & & \\
\hline \multicolumn{11}{|l|}{ Age-2 } \\
\hline Age-3 & 12.09 & 12.09 & 12.09 & 12.09 & 12.09 & 12.09 & 12.09 & & 12.09 & 12.09 \\
\hline Sex-1 & & & & & & & & & 21.68 & \\
\hline Sex-2 & -21.68 & -21.68 & -21.68 & -21.68 & -21.68 & -21.68 & -21.68 & -21.68 & & -21.68 \\
\hline School-1 & -9.51 & -9.51 & -9.51 & -9.51 & -9.51 & -9.51 & -9.51 & -9.51 & -9.51 & \\
\hline School-2 & & & & & & & & & & 9.51 \\
\hline $\begin{array}{l}\text { Estimated } \\
\text { price }\end{array}$ & 351 & 396 & 401 & 378 & 378 & 369 & 330 & 335 & 394 & 370 \\
\hline Difference & 0.0 & 45.0 & 50.3 & 26.8 & 27.4 & 17.8 & -21.1 & -16.2 & 43.4 & 19.0 \\
\hline $\begin{array}{l}\text { Difference } \\
\text { in } \%\end{array}$ & 0 & 13 & 14 & 8 & 7 & 5 & -6 & -5 & 12 & 5 \\
\hline
\end{tabular}




\section{Types of fonio}

Not surprisingly, fonio types are the most determinant variables (VIP $=1.44$ for decorticated and 2.07 for milled and washed). The name of the category itself - decorticated, milled, milled and washed - has a significant impact on the price: "decorticated" fonio costs 17 FCFA $(15.08+1.58$, Model 2, Table 3) less than the average milled fonio and 50 FCFA (14\%) less than the milled and washed one (sim2, Table 4). It is very interesting to note that the type of fonio is more important in explaining the price level than the perceived cleanliness. On the contrary, it does not eradicate the effects of colour nor level of milling as could have been expected.

\section{Level of milling}

This characteristic had a very significant effect on the price, from -13.92 to $+12.84 \mathrm{FCFA} / \mathrm{kg}$ (Model 2, Table 3). For the given example, it represented $8 \%$ of the price increase from badly to very well decorticated fonio (sim3).

\section{Colour}

The hedonic price of the red/brown fonio is $-12.81 \mathrm{FCFA} / \mathrm{kg}$, while the hedonic price of the cream-white fonio is $+14.56 \mathrm{FCFA} / \mathrm{kg}$. The difference represented $7 \%$ of the global price $(\operatorname{sim} 4)$.

\section{Country of origin}

The hedonic price of fonio from Mali is -13 FCFA $/ \mathrm{kg}$, which completely confirmed our expectations after conducting the qualitative survey. Fonio from Guinea is valued 15.81 FCFA $(+4 \%)$ more than the reference coming from Mali, whereas Fonio with unknown origins costs even more, +17.8 FCFA $(\operatorname{sim} 5)$.

\section{Profession}

"Professionals" paid a lower price $(-21.1 \mathrm{FCFA} / \mathrm{kg}$, sim6) than other buyers for final home consumption $(-6 \%)$. This is not surprising: these people are more used to the market and the product and are more able to discuss the prices.

\section{Age}

Older buyers ( $>50$ years old) paid more than others $(+16.2 \mathrm{FCFA} / \mathrm{kg}$ ) or $+5 \%$ $(\operatorname{sim} 7)$ in our example. We had thought that age would be a good proxy/indicator/ determinant of knowledge, hence of bargaining power; however, this is obviously not the case. One interpretation of this unexpected result may be found in the link between health and age. During the interviews, it was indeed often said that fonio was "healthy" and good for sick or elderly people. It is thus possible that the elderly have a stronger preference for fonio than younger ones and are less reluctant to pay for it at a high price.

Sex

The price paid for fonio by a woman is $43.4 \mathrm{FCFA} / \mathrm{kg}$ less than the price paid by a man. In our example, a man pays $12 \%$ more for the same product (sim8). Sex is the fourth most important variable both in terms of absolute value and in terms of VIP, 
after the Riverside market and the types of fonio (decorticated and washed). Two interpretations can be given for this result, the first being our preferred since it responds to a more positive perspective. It emphasises women's greater knowledge and their ability to recognise the different quality attributes and to discuss them. In a way, they are less "cheated" than men since they are the ones who usually cook and do the shopping. They have a comparative advantage in knowledge and bargaining. The second interpretation that must be mentioned here - fitting well with the usual feminist literature (Agarwal, 1997) - explains that women are usually poorer than men and thus have to bargain more to fulfil their requirements. Nothing in the present data and study has allowed a clear conclusion between these two interpretations since data on income and wealth is scarce.

\section{School level}

People who never went to school or only up to the primary level paid less $(-19 \mathrm{FCFA} / \mathrm{kg}$ or $-5 \%$, sim 9$)$ than those who reached higher levels of education. This may be explained by the fact that people with more education have higher income and wealth and are less constrained by price.

\subsection{Discussion}

Altogether, the range of the premiums paid for quality attributes varies from 5 to $14 \%$. These premiums are comparable to those of other studies on staple food in Africa (Languyinto, Lançon, Vandeplas op. cit.).

The estimation of a hedonic price for most characteristics showed that the informal market institution "works" in segmenting the quality or at least some aspects of quality.

The hedonic estimates provided a clearer image on what is valued in the existing retail market. On average, cleanliness, size, and hardness of the grain, as perceived by the buyers, had no influence on the price. On the other hand, colours as well as levels of milling (badly versus well or very well decorticated) had a very specific effect on the price.

In addition to these technical, visible characteristics, more sophisticated product characteristics - such as the type of the product, which is a really complex social construction, and the origin, which is difficult to verify - had specific effects on the price and specific hedonic prices.

In other words, the retail markets function according to the urban consumers' point of view. What most people say they like has a specific higher price than what they say they dislike.

This works for simple attributes as well as for less complex ones, which confirms that a minimum of trust (for example, fonio origin) and common norms (definition of each type) exist in these retail markets. The findings of other authors previously referred to here and those of more recent studies, such as Lyon and Porter (2009) are thus also confirmed. As a result, we advocate caution with regards to the implementation of formal norms. They may be ineffective or even costly and counterproductive for certain types of attributes. 
One can, however, argue against the fact that the consumers' perceptions of quality depend on the existing available products and also that certain aspects of quality that do not exist yet would be valued if they were created and protected by some special norms or systems of certification (Masters and Sanogo, 2002; Tallec and Egg, 2009).

\section{Conclusion}

This example of the hedonic estimation approach has shown that Malian buyers pay, on average, a higher price for their preferred attributes, such as cream-white colour, better milling, and Guinea origin. While the difference between various products, with or without the specific attribute, is small - from 1 to $12 \%$ - it is nevertheless significant.

Most valued attributes are physical and linked to the product (level of milling, colour), but others (country of origin) are not visible and require a certain amount of trust between retailers and buyers. This study reveals that in one of the poorest countries in the world, informal market institutions/rules allow to finely distinguish several kinds of sub-products and, among these various sub-products, different kinds of qualities, including unverifiable attributes.

This is one contribution to the knowledge of existing African food markets. It does not prove that markets are fully efficient or perfect, but it has hopefully shown that, in this specific case, they can provide differentiated products, at least for most desired attributes. Other specific studies would be needed to uncover other characteristics that are not verifiable and for other products. Anyhow, it encourages developers to look closer into the existing "informal" market institutions before promoting formal regulation systems.

\section{References}

Alpha A., Broutin C., Hounhouigan J.D., Anihouvi V. (2009) Normes de qualité pour les produits agroalimentaires en Afrique de l'Ouest, Paris, Agence Française de Développement, série Notes et documents, 229 p.

Agarwal B. (1997) "Bargaining" and Gender Relations: Within and Beyond the Household, Feminist Economics 3-1, 1-51.

Bessler D.A., Kergna A. (2003) Price Discovery: The Case of Millet in Bamako, Mali, Journal of African Economies 11-4, 472-502.

Bricas N., Cheyns E. (2003) La construction de la qualité des produits alimentaires. Le cas $d u$ Soumbala, des céréales et des viandes sur le marché de Ouagadougou au Burkina Faso, Montpellier, Cirad, 82 p.

Chaléard J.L. (1996) Temps des villes Temps des vivres L'essor du vivrier marchand en Côte d'Ivoire, Paris, Karthala, 601 p. 
Cheyns E. (1998) Identification et construction sociale de la qualité des produits agroalimentaires. Le cas de l'alimentation urbaine au Burkina Faso. Thèse de doctorat en économie du développement agricole, agro-alimentaire et rural, ENSAMUniversité Montpellier I, 381 p. + annexes.

Cheyns E. (2006) Format d'enquêtes. Expériences de recherche autour des processus de qualification des produits alimentaires en Afrique. In : L'économie des conventions, méthodes et résultats, Tome 2 : Développements, Eymard Duvernay F. (ed) Paris, La Découverte, coll. Recherches.

Clark G. (1994) Onions are my Husband. Survival and accumulation by West African Market Women, Chicago, The University of Chicago Press, 488 p.

Colwell P.F., Munneke H.J. (2006) Bargaining Strength and Property Class in Office Markets, the Journal of Real Estate Finance and Economics 33, 197-213.

Cruz J-F. (2009) Le fonio, une céréale ancestrale remise au goût du jour. Travaux et Innovations $163,30-35$.

Dury S., Meuriot V., Fliedel G., Blancher, Bore Guindo F., Drame N., Bricas N., Diakite L. et Cruz J.F. (2007) The retail market prices of fonio reveal the demand for quality characteristics in Bamako, Mali. Communication at the 106th seminar of the European Association of Agricultural Economists "Pro-poor development in low income countries: Food, agriculture, trade, and environment", Montpellier, France, 25-27 October, 15 p.

Dury S., Bricas N., Tchango-Tchango J., Temple L., Bikoï A. (2002) The determinants of urban plantain consumption in Cameroon, Food Quality and Preferences 32-3, 81-88.

Egg J., Moustier P., Tallec F. (2006) Coordination et qualité dans les filières agricoles du Sud, Montpellier Moisa, Série Cabier de Recherche 4, 87 p.

Harding J.P., Rosenthal S., Sirmans C.F. (2003) Estimating bargaining power in the market for existing homes, The Review of Economics and Statistics 85-1, 178-188.

Konkobo-Yameogo C., Chaloub Y., Kergna A., Bricas N., Karimou R., Ndiaye J-L. (2004) La consommation urbaine d'une céréale traditionnelle en Afrique de l'Ouest : le fonio, Cabiers Agricultures 13-4, 125-128.

Kumbhakar S.C., Parmeter C. (2009) Estimation of hedonic price functions with incomplete information, Empirical Economics 39-1, 1-25.

Lancaster K. J. (1966) A New Approach to Consumer Theory, The Journal of Political Economics 74, 132-156.

Lançon F., Erenstein O., Touré A., Akpokodje G. (2004) Qualité et compétitivité des riz locaux et importés sur les marchés urbains ouest-africains, Cabiers Agricultures $13,110-115$.

Langyintuo A.S., Lowenberg-DeBoer J., Faye M., Lambert D., Ibro G., Moussa B., Kergna A., Kushwaha S., Musa S. Ntoukam G. (2003) Cowpea supply and demand in West and Central Africa, Field Crops Research 82, 215-231. 
Langyintuo A.S., Ntoukam G., Murdock L., Lowenberg-DeBoer, Miller D.J. (2004) Consumer preferences for cowpea in Cameroon and Ghana, Agricultural Economics 30, 203-213.

Lyon F., Porter G. (2009) Market institutions, trust and norms: exploring moral economies in Nigerian food systems, Cambridge Journal of Economics 3, 903-920.

Masters W.A., Sanogo D. (2002) Welfare Gains from Quality Certification of Infant Foods: Results from a Market Experiment in Mali, American Journal of Agricultural Economics 84-4, 974-989.

Rosen S. (1974) Hedonic Prices and Implicit Markets: Product differentiation in Pure Competition, The Journal of Political Economy 82 (1), 34-55.

Tallec F., Egg J. (2009) Contraintes aux démarches qualité dans les filières mil-sorgho au Sahel, Cabiers Agricultures 18-1, 50-55.

Tenenhaus M. (1998) La régression PLS - Théorie et pratique, Paris, Edition Technip.

Vanderplas A., Minten B., Swinnen, J.F.M. (2009) On food quality in domestic markets of developing economies. Contributed Paper prepared for presentation at the International Association of Agricultural Economists Conference, Beijing, China.

Stoica P., Söderström D. (1998) Partial Least Squares: A First-order Analysis, Scandinavian Journal of Statistics 25, 17-24.

Wold S., Ruhe A., Wold H., Dunn, W.J. (1984) The Collinearity Problem in Linear Regression. The Partial Least Squares (PLS) Approach to Generalized Inverses, SIAM Journal of Scientific and Statistical Computing 5-3, 735-743. 